\title{
Informação, conhecimento e Direitos de Propriedade Intelectual: os limites dos mecanismos de mercado e das modalidades de negociação privada A contribuição de Williamson à análise dos Direitos de Propriedade Intelectual ${ }^{*}$ Alain Herscovici ${ }^{* *}$
}

\begin{abstract}
Resumo
Este artigo se propõe a demonstrar que as análises que preconizam a extensão da negociação privada no que diz respeito ao Conhecimento, à Informação e aos Direitos de Propriedade Intelectual não constituem instrumentos adequados pelo fato de dependerem de hipóteses que não correspondem às particularidades desses ativos: racionalidade substantiva, contratos completos e ausência de incerteza. Após apresentar os fatos estilizados e os principais elementos teóricos desse debate, ressaltarei os limites explicativos dessa abordagem e proporei uma análise alternativa baseada nos conceitos de especificidade dos ativos, no sentido definido por Williamson. A esse respeito, mostrarei em que consistem as complementaridades entre o mercado e as instituições.
\end{abstract}

Palavras-chave: Custos de transação; Direitos de Propriedade Intelectual; Instituições.

\begin{abstract}
Information, knowledge and Intellectual Property Rights: the limits of market mechanisms and private negociation. The contribution of Williamson to the analyse of Intellectual Property Rights

This article aims to demonstrate that the analysis that advocates an extension of private logic in regard to Information, Knowledge and Intellectual Property Rights does not constitute an appropriated framework as it depends on hypotheses that do not correspond to the specificities of such assets: substantive rationality, complete contracts and absence of uncertainty. After presenting the stylized facts that match this economy and the main elements of the theoretical debate, it is underlined the explanatory limits of this approach and proposed an alternative analysis based on the concepts of asset specificities in the sense defined by Williamson. In this respect, I will stress the necessary complementarities between market and institution.
\end{abstract}

Keywords: Transaction costs; Intellectual Property Rights; Institutions.

JEL D23, O34.

\section{Introdução}

O período atual caracteriza-se pela ampliação dos Direitos de Propriedade (DP), mais especificamente dos Direitos de Propriedade Intelectual (DPI). Essa

${ }^{*}$ Trabalho recebido em 8 de julho de 2009 e aprovado em 18 de setembro de 2011.

${ }^{* *}$ Coordenador do Grupo de Estudo em Macroeconomia (GREM) e do Grupo de Estudo em Economia da Cultura, da Comunicação, da Informação e do Conhecimento (GEECICC), Programa de Pós-Graduação em Economia (PPGEco) da Universidade Federal do Espírito Santo (UFES) / Professor do PPGEco e pesquisador do CNPq, Vitória, ES, Brasil. E-mail: alhersco.vix@terra.com.br. Agradeço os comentários de dois pareceristas anônimos, que permitiram redefinir a problemática, retificar certos erros de interpretação e melhorar substancialmente este trabalho. Obviamente, continuo sendo inteiramente responsável pelo conteúdo deste artigo. 
ampliação relaciona-se simultaneamente com as atividades sociais que podem ser objeto de tais direitos, com os agentes que podem detê-los e com as modalidades de valorização econômica das diferentes formas de capital intangível, implementandose principalmente no âmbito de uma lógica privada, ou seja, de uma lógica de mercado.

Por outro lado, a nova economia institucional considera que o mercado não mais pode ser concebido como uma instância abstrata, uma "caixa preta" regulada apenas pelo sistema de preços concorrenciais; a implementação de mecanismos de coordenação necessários ao funcionamento desses mercados se traduz por um certo nível de custos de transação (CT). Enquanto a análise walrasiana considera apenas os custos de produção, as diferentes vertentes da economia institucional acrescentam, a esses custos, os custos de transação; a eficiência das diferentes modalidades de governança será avaliada a partir do nível dos custos de transação.

A interpretação que Stigler (1966) faz do texto de Coase "The problem of social cost" é totalmente neoclássica Obviamente, ele mantém as hipóteses ontológicas que caracterizam a matriz walrasiana: racionalidade substantiva dos agentes, ausência de incerteza e eficiência dos mercados concorrenciais. Em função dessas hipóteses, essa interpretação chega à conclusão de que o mercado é sistematicamente a instância mais eficiente nas seguintes situações: (a) quando, como considera o próprio Stigler (1996), os CT são nulos, por hipótese; (b) quando os CT representam apenas imperfeições de curto prazo que desaparecem no longo prazo ou (c) quando os CT são positivos no curto e longo prazo. Neste último caso, o mercado é a instância que minimiza sistematicamente esses CT. Neste trabalho, a partir das especificidades econômicas do conhecimento, ressaltarei os limites teóricos desse tipo de análise. A partir do conceito de complexidade dos bens e dos ativos intangíveis, o qual se relaciona estreitamente com o conceito de especificidade dos ativos no sentido definido por Williamson, desenvolverei uma análise alternativa que incorpora as hipóteses de racionalidade limitada dos agentes e de incerteza forte no sentido pós-keynesiano.

É importante ressaltar o fato de que esta análise dos DPI se relaciona diretamente com a análise econômica dos DP: por um lado, na tradição do direito anglo-saxão, os DP são concebidos como um feixe (bundle) de direitos relativos à utilização de um determinado fator de produção (Alchiam; Demsetz, 1973, p. 17). Assim, os DP não são definidos em função da posse material do ativo, mas das diferentes utilizações que serão feitas desse ativo e dos retornos assim gerados. Nessa perspectiva, não importa que o objeto seja tangível ou intangível: o DP relacionase diretamente com a utilização desse ativo. Por outro lado, a análise institucional aplica-se a objetos sociais tão diferentes como o funcionamento das comunidades "primitivas" e o compartilhamento dos recursos naturais, a evolução dos sistemas 
de microcrédito e os sistemas de compartilhamento do conhecimento, no caso dos programas Open Source (Ostrom; Hesse, 2007, p. 7). Independentemente do ativo considerado, trata-se de determinar o sistema de DP viável, ou seja, compatível com uma modalidade de governança na qual os custos de transação não sejam proibitivos.

Na primeira parte do artigo, explicitarei as especificidades econômicas dos bens e serviços ligados à Informação e ao Conhecimento, mostrando, a partir de fatos estilizados, como se manifestam concretamente as falhas de mercado. A partir de uma análise econômica dos comuns (commons), estudarei a relação entre o sistema de DPI, a modalidade de governança escolhida e o nível dos CT, apresentando os principais elementos do debate teórico relativo à natureza e à função dos CT. $\mathrm{Na}$ segunda parte, são ressaltadas as oposições metodológicas entre a vertente neoclássica e a análise de Williamson, notadamente a possibilidade de incorporar a incerteza forte, explicitando os componentes relativos à escolha de uma modalidade de governança. Na linha dos trabalhos de Williamson, Ostrom, Cox e Barzel, são demarcados os limites da negociação privada dos DP e formalizados os principais mecanismos que permitem explicar as diferentes "falhas de mercado" próprias a uma negociação privada.

\section{Informação, conhecimento e bens públicos: especificidades econômicas e custos de transação}

\section{A natureza econômica da informação e do conhecimento}

\subsection{As especificidades econômicas dos bens públicos e o caráter cumulativo da produção}

A Informação e o Conhecimento caracterizam-se pela não exclusividade, pela não rivalidade e pelo caráter cumulativo da produção:

i) A não exclusividade significa que o agente que produz o conhecimento não tem condições de controlar plenamente suas modalidades de apropriação: conhecimento, este, que produz intrinsecamente externalidades positivas que podem ser apropriadas pelos diferentes agentes. Essas externalidades positivas se relacionam com saberes abertos ${ }^{1}$ (Foray, 2000, p. 80) e com a existência de clubes e redes também abertos. A função de bem-estar social depende diretamente do grau de abertura desse clube: quanto maior o grau de abertura, mais importantes as externalidades e mais cumulativo o conhecimento assim produzido

ii) A não rivalidade se explica pelo fato de o conhecimento não ser destruído no ato do consumo: o consumo de um indivíduo não implica que esse bem não possa ser consumido por outros indivíduos, o que ressalta o caráter indivisível do consumo.

(1) Este conceito se assemelha ao que certos autores chamam de ciência aberta (Orsi, 2002, p. 78) ou de scientific commons (Nelson, 2003). 
Essas duas primeiras características se aplicam igualmente à Informação.

iii) O caráter cumulativo do Conhecimento expressa o fato de que a taxa de crescimento de sua produção depende do nível do estoque inicial; o conhecimento é utilizado como insumo para produzir mais conhecimento. $\mathrm{O}$ conhecimento se caracteriza por rendimentos crescentes, o que constitui os fundamentos das teorias do crescimento endógeno (Romer, 1990). Por outro lado, esse caráter cumulativo ressalta claramente a interdependência dos diferentes agentes no que diz respeito ao processo de produção do Conhecimento.

A dependência bi e multilateral caracteriza as modalidades de produção: consequentemente, aparece uma incerteza comportamental forte na medida em que a função de produção de um agente depende diretamente do comportamento do conjunto dos outros produtores. Por outro lado, a existência de contratos e o sistema de DPI vigente são elementos que devem diminuir essa incerteza. Em função do caráter de bem público, coloca-se o problema relativo aos comportamentos oportunistas que os diferentes agentes podem desenvolver.

\subsection{Bens de experiência e assimetrias da informação}

Os mercados ligados à economia digital caracterizam-se por importantes assimetrias de informação entre produtores, entre consumidores e produtores, e entre consumidores ${ }^{2}$. Esses bens e serviços são bens de experiência (experience goods): em função da complexidade e quantidade de conhecimento codificado neles embutido, decorrentes da dependência generalizada que caracteriza o funcionamento das redes, o consumidor não pode avaliar, ex ante, sua utilidade (Salop, 1976). $\mathrm{O}$ sistema de preços não fornece informações relevantes no que diz respeito às características qualitativas desses bens. Assim, a utilidade do bem só será conhecida durante o ato do consumo.

As implicações são as seguintes: os limites relativos à informação fornecida pelo sistema de preços têm que ser compensados por outros mecanismos que visam diminuir a incerteza relativa à avaliação dos componentes qualitativos: o desenvolvimento das diferentes comunidades on-line é justamente um desses mecanismos. Essas comunidades compensam as falhas do sistema de preços, diminuem a incerteza relativa à qualidade dos produtos consumidos e permitem diferenciar os produtos a partir de uma lógica de marca. É possível afirmar que essas comunidades on-line cumprem o mesmo papel que o dos críticos no campo da produção artística: permitem criar o capital simbólico, ou seja, a utilidade social prévia necessária à valorização econômica dos produtos e dos serviços. É importante observar que as modalidades da concorrência se modificaram: na análise tradicional, as estratégias de marca (brand name) são consideradas como anticoncorrenciais na

(2) Para uma análise detalhada deste ponto, ver Herscovici (2008). 
medida em que se traduzem por uma diferenciação do produto e por preços mais altos do que aqueles de concorrência pura e perfeita. Não obstante, essa estratégia permite minimizar os custos de busca (search costs) do consumidor e, consequentemente, o custo total que ele tem que pagar (Posner, 2005, p. 67).

\section{As "falhas" de mercado: alguns fatos estilizados}

\subsection{A extensão da "patenteabilidade" e suas implicações}

Esse debate relaciona-se diretamente com o domínio de aplicabilidade dos DPI. Uma invenção pode ser objeto de uma patente quando ela é útil, ou seja, quando apresenta uma utilidade prática e comercial (Orsi, 2002, p. 72). Até os anos 80, os tribunais americanos, nas suas ações de jurisprudência, limitavam a "patenteabilidade" às invenções, ou seja, a aplicações práticas e definidas de certos processos. No entanto, hoje, as modificações do conceito de utilidade se traduzem, de fato, por uma redefinição das fronteiras, por uma ampliação do campo de aplicação dos DPI e por uma privatização dos scientific commons e do conjunto dos bens patrimoniais. Processos ligados às combinações genéticas ou aos algoritmos utilizados nos programas informáticos são objetos de DPI.

No que diz respeito ao primeiro ponto, a jurisprudência americana, imitada pela jurisprudência europeia, modificou-se radicalmente, ampliando o campo de aplicação dos DPI e modificando a dicotomia tradicional entre o público e o privado, entre conhecimento aberto e conhecimento fechado. Hoje, os DPI se relacionam com processos definidos genericamente cujas aplicações não são previsíveis nem identificáveis (Orsi, p. 25) (códigos genéticos e algoritmos informáticos). Essa extensão de fronteiras se traduz por um deslocamento dos DPI das aplicações tecnológicas identificadas para os conceitos genéricos dos quais provêm essas inovações (Idem, p. 23).

Esse contexto implica em uma intensificação da incerteza ligada à valorização desses ativos intangíveis: (a) na medida em que as aplicações tecnológicas de determinado processo genérico não são identificáveis, ex ante, não é possível prever as receitas que esse ativo pode gerar; (b) considerando-se que a produção de conhecimento é, por natureza, altamente cumulativa e que há uma fragmentação dos DPI, esses investimentos representam uma atividade cuja valorização é particularmente aleatória: a patente que uma firma A pode depositar depende do fato de que ela possa utilizar algoritmos detidos por B, C e D, por exemplo.

A esse respeito, Posner afirma que o sistema de DPI só pode ser aplicado às expressões de certas ideias, e não às ideias em si (2005, p. 64-65). A argumentação é que a transformação da ideia em uma aplicação prática comercial é altamente incerta e, consequentemente, não pode ser objeto de direitos de propriedade. No entanto, 
as evoluções do sistema de DPI, a partir da metade dos anos 80, são diferentes: a redefinição das fronteiras do sistema de DPI mostra claramente que esse sistema se estende para as ideias; assim, a valorização torna-se particularmente aleatória (Arrow, 1962). As modalidades concretas de implementação de tal sistema de DPI se traduzem, de fato, pelo aumento dos custos de transação e pelo desenvolvimento de estratégias de rent seeking (Posner, 2005, p. 65).

Estudos empíricos mostram que, de 1980 até hoje, não há uma correlação positiva entre a quantidade de patentes registradas e o progresso técnico, que pode ser avaliado a partir das despesas em Pesquisa e Desenvolvimento. A um aumento da taxa de crescimento do número de patentes registradas não corresponde um aumento proporcional da taxa de crescimento das despesas em P \& D (Lebas, 2002, p. 252). As teses de inspiração neoclássica não são verificadas na medida em que a ampliação dos DPI não se traduz por uma intensificação das incitações a inovar. Esse fenômeno ressalta a modificação da natureza e da função dos DPI: as firmas praticam uma estratégia sistemática de constituição de portfólio de DPI sem nenhuma relação com a intensificação do progresso técnico. A patente não é mais concebida como um meio de se apropriar de uma renda de monopólio temporário relativa à inovação tecnológica (Idem, p. 254); o segredo é preferido à difusão da inovação. Quanto mais a patente se relaciona com processos, e não com produtos, maior o poder de mercado da empresa que detém esse direito. A implementação desse tipo de barreira à entrada se traduz numa diminuição da concorrência nesses mercados.

\subsection{Os fatos estilizados}

Há, igualmente, um elemento que vem acentuar a incerteza ligada às receitas que essas patentes podem propiciar à medida que a efetivação de determinada patente por parte de uma firma A pode ser bloqueada pelas patentes que B, C e D possuem. Esses mercados se caracterizam por uma forte endogeneização das externalidades produzidas pelo progresso técnico, endogeneização realizada no seio de redes fechadas ou semifechadas. As barreiras à entrada, assim construídas, limitam as externalidades de oferta e o caráter cumulativo do progresso técnico. Por outro lado, essas estratégias se traduzem por falhas de coordenação que ressaltam o fato de que esses mercados não são eficientes.

Essa fragmentação da propriedade intelectual permite, consequentemente, praticar estratégias de hold-up. Em função do caráter altamente cumulativo da produção de certos processos (biotecnologias e programas informáticos), as firmas que não alcançam determinada massa crítica em termos de DPI não podem penetrar no mercado e, na medida em que os processos tecnológicos que querem implementar contêm componentes protegidos, sua entrada é impedida. Essas firmas são objeto de uma estratégia de hold-up por parte das firmas que já atuam no mercado. Por outro 
lado, tais estruturas de mercado se traduzem por um risco maior no que diz respeito ao valor das patentes.

Esses exemplos ressaltam claramente que, no âmbito de uma lógica de mercado, uma intensificação dos DPI se traduz em um aumento dos custos de transação. Posner (2005, p. 59) chega a conclusão semelhante e ressalta as diferenças, de um ponto de vista econômico, entre os direitos de propriedade que se aplicam aos bens tangíveis e às produções intelectuais. A esse respeito, coloca em evidência o fato de que, em função das especificidades econômicas das diferentes produções intelectuais, os custos de transação ligados a esses bens são mais altos do que aqueles que se relacionam aos os bens tangíveis (Idem, p. 61).

\section{Tragédia dos commons, tragédia dos anticommons e DPI}

\subsection{Comuns versus anticomuns?}

Quando se trata de um bem comum em uma determinada coletividade (componentes ecológicos, recursos naturais, conhecimento comum etc.), a apropriação privada de tais bens pode ser prejudicial à comunidade: geralmente, se traduz pelo esgotamento do estoque disponível.

Hardin (1968, p. 1243) explica o fracasso da propriedade comum pela ausência de um sistema institucional capaz de preservar o estoque desse bem comum. O exemplo do lago ilustra esse tipo de situação: se o lago for um bem comum, cada pescador vai maximizar seu ganho, o que não é compatível com a preservação do estoque de peixes. A solução consiste em implementar um princípio de coerção: a propriedade privada do lago cumpre essa função e permite evitar a exaustão do estoque de peixes. Hardin explica, dessa maneira, as enclosures no final do século XVII.

Os limites dessa tese são os seguintes:

i) No caso da apropriação privada dos recursos que provêm do bem comum, existem outros meios para regular o sistema. Nas diferentes coletividades, há convenções e regras que determinam e controlam as modalidades de apropriação social desses bens. As diversas formas de propriedade coletiva não podem ser assimiladas à ausência de propriedade (Orstom, 2000, p. 335); geram regras e convenções explícitas e/ou implícitas que os membros da coletividade têm que seguir, o que permite controlar os comportamentos oportunistas e minimizar as implicações ligadas a tais comportamentos para um nível de custo de transação compatível com o funcionamento do sistema. Contrariamente à tese de Hardin, o fim do sistema baseado na propriedade comum das terras na Inglaterra se explica a partir da atuação dos fazendeiros mais ricos, ou seja, do não respeito desses mecanismos de coerção (Cox, 1986, p. 60). 
ii) É preciso, igualmente, diferenciar as situações em função da natureza econômica do bem comum. Quando os recursos obtidos do bem comum são bens privados e divisíveis, "the benefits consumed by one individual subtract from the benefits available to others" (Orstom, 2000, p. 337). A situação é, no entanto, distinta quando se trata de bens públicos indivisíveis. De fato, a explicação de Hardin só faz sentido no caso de os bens serem privados e totalmente divisíveis.

Quando, ao contrário, se trata de bens públicos distribuídos no seio de redes, as externalidades positivas dependem diretamente da quantidade de usuários/ participantes. No caso das redes eletrônicas, as externalidades de demanda expressam essa relação (Katz; Shapiro, 1985). É possível observar a existência desse tipo de externalidade na indústria de softwares e nos sistemas de compartilhamento de arquivos digitais (Herscovici, 2007). Na presença de bens públicos, as modalidades de apropriação privada desses bens provocam falhas de mercado importantes: o processo de exclusão pelos preços se traduz pela diminuição do número de participantes e da qualidade indivisível do serviço disponível para o conjunto da comunidade. Esse contexto representa uma limitação das externalidades positivas e da taxa de crescimento da produção, conforme ressalta o exemplo da privatização dos scientific commons (Nelson, 2003).

Por outro lado, o nível dos custos de transação necessário para controlar e conter os comportamentos oportunistas que se desenvolvem a partir do caráter não rival desses bens é alto demais (Demsetz, 1964, p. 16). Para diminuir esses custos a um nível compatível com a produção de tais bens, a solução consiste em modificar a natureza dos DPI e, eventualmente, a modalidade de governança.

Os anticommons (Heller; Eisenberger, 1998) se caracterizam pelo fato de o Conhecimento ser o objeto de DPI múltiplos; nesse caso, o jogo de mercado produz externalidades negativas e importantes falhas de mercado. Há um aumento dos custos de transação relativos à aquisição dos diferentes processos necessários à implementação de uma determinada tecnologia na medida em que os utilizadores têm que negociar esses direitos com vários titulares ${ }^{3}$. Quando há vários titulares dos DPI necessários à adoção de uma determinada inovação tecnológica, o preço será comparativamente mais alto do que na situação em que há apenas um titular. O desenvolvimento dos comportamentos oportunistas faz com que apareçam externalidades de demanda ${ }^{4}$ : externalidades que produzem falhas de mercado e se traduzem por uma diminuição do bem-estar. Nessa situação, os preços relativos à aquisição da tecnologia são mais altos que os preços concorrenciais.

A privatização das modalidades de apropriação da produção científica e tecnológica se traduz pelo desenvolvimento dos comportamentos predadores e pela

(3) A esse respeito, ver, igualmente, Posner (2005, p. 69).

(4) Trata-se de externalidades de demanda no sentido definido pelos novos keynesianos. 
queda da taxa de crescimento da produção em função do caráter cumulativo desse tipo de atividade, o que traduz a ineficiência dos mecanismos de negociação privada (Nelson, 2003).

Na perspectiva desenvolvida neste trabalho, essas falhas de mercado se explicam a partir da incompatibilidade entre modalidades de apropriação privada ligadas a um sistema de DPI privado e a produção de bens públicos não rivais e não exclusivos. Conforme mostram Alchian e Demsetz (1973, p. 23), a tragédia dos commons se explica a partir da contradição entre um sistema de DP coletivo e a apropriação privada dos bens. Se o fruto da pesca, por exemplo, fosse dividido igualmente entre os diferentes membros da comunidade, independentemente das contribuições individuais, não haveria comportamentos oportunistas ${ }^{5}$. A apropriação privada de um bem público, ou semipúblico, explica a existência e o desenvolvimento dos comportamentos oportunistas.

Há duas maneiras de controlar ou eliminar parcialmente esses comportamentos oportunistas: excluir os DP privados no que concerne ao consumo ou, ao contrário, privatizar a propriedade do bem comum. O primeiro caso corresponde a formas de economia cooperativa nas quais: (a) a apropriação privada não é determinada a partir da contribuição individual de cada agente, mas em função de outros princípios de redistribuição ${ }^{6}$ e (b) a propriedade do bem públicoé coletiva. Esta última característica não significa que há ausência de propriedade e de regras de comportamentos. Tratase de privatizar o estoque de bem comum; nesse caso, a preservação do estoque será assegurada a partir do comportamento "racional" do proprietário privado: a exclusão pelos preços permite eliminar os comportamentos oportunistas.

É preciso acrescentar as seguintes observações: a escolha entre um sistema coletivo ou privado de DP depende, em parte, da natureza econômica do bem considerado. No que diz respeito a um bem público, os custos de transação necessários para controlar os comportamentos oportunistas podem ser proibitivos. A escolha de uma modalidade de governança será feita em relação a um mesmo nível de produção a partir do nível dos custos de transação relativo a cada uma dessas modalidades; por outro lado, esse nível dos custos de transação depende diretamente da natureza econômica dos bens e do sistema de DP vigente. A esse respeito, Barzel (1997, p. 4-5) define os custos de transação como “ (...) the costs associated with the transfer, capture and protection of rights". O sistema de DP deve ser compatível com um nível de custos de transação que permita implementar a produção e a distribuição dos bens e serviços considerados. Existe, assim, uma determinação recíproca entre os custos de transação e o sistema de DP: por um

(5) Não obstante, esses autores acrescentam que, nesse caso, os agentes econômicos não teriam mais incentivos para aumentar seu produto.

(6) Corresponde ao funcionamento das redes de compartilhamento de arquivos, às modalidades de produção e de distribuição dos programas livres e aos scientific commons. 
lado, a implementação de um determinado sistema de DP implica certos custos de transação, por outro, se esse nível é proibitivo, é preciso modificar o sistema de DP para viabilizar essa produção.

Os DPI têm que ser concebidos como um feixe de direitos: acesso, contribuição, extração, subtração, administração e participação, exclusão e alienação (Ostrom; Hesse, 2007, p. 17-18). A passagem de um sistema de DP privado para um sistema comum consiste em ceder alguns desses direitos para criar um capital social (Bowles; Gintis, 2000), ou seja, um bem público. No caso dos programas livres, a construção desse comum se implementa a partir da cessão dos componentes ligados ao acesso e à alienação e do desenvolvimento das atividades ligadas à contribuição dos diversos participantes. As diferentes comunidades científicas, por exemplo, funcionam da mesma maneira.

A tragédia dos comuns, assim como a tragédia dos anticomuns, se explica pela incompatibilidade entre a natureza econômica dos bens e serviços consumidos e o sistema de DP vigente. No caso apresentado por Hardin, as divergências entre o bem-estar social e as racionalidades microeconômicas se evidenciam pelo fato de que a ausência de propriedade, no que diz respeito aos recursos que provêm do estoque comum, é incompatível com a natureza privada dos bens consumidos. No caso da tragédia dos anticomuns, a apropriação privada e o sistema de DP privado são incompatíveis com a natureza pública dos componentes do estoque disponível. Nos dois casos, os mecanismos de governança não são socialmente eficientes.

\subsection{DPI e novas formas de Propriedade Intelectual}

É na economia digital que as diferentes formas de economia solidária apresentam a maior eficiência social. Os sistemas dos comuns baseados no compartilhamento de informações e bens culturais são social e economicamente mais eficientes que os sistemas baseados na propriedade privada e na distribuição a partir de suportes materiais individualizados.

No que diz respeito à indústria da música, por exemplo, os mecanismos de criação e apropriação do valor são baseados em um sistema de DPI privado diretamente ligado a modalidades privadas de apropriação a partir de suportes materiais individualizados (livros, CD etc.) com pagamentos também individualizados por parte dos consumidores. Essas modalidades de regulação de mercado correspondem ao modelo analógico que caracterizava as indústrias culturais até a era digital. $\mathrm{O}$ desenvolvimento das redes eletrônicas corresponde a modificações radicais no que diz respeito às modalidades de produção, de financiamento e de apropriação desses bens: na medida em que o modo de apropriação se modificou, o sistema de DPI 
e de financiamento tem que acompanhar essas evoluções (Romer, 2002). De um ponto de vista geral, o desenvolvimento da economia digital se traduz por um duplo movimento: a transformação da natureza econômica dos bens e dos serviços e dos sistemas de DPI correspondentes.

A maior parte dos bens pode ser assemelhada a bens públicos, cujas principais características são a não exclusão e a não rivalidade. A concorrência consiste em internalizar as externalidades de redes presentes nesses mercados. Em função dessas especificidades, não é possível maximizar funções microeconômicas de lucro, igualando custos e receita marginal (Herscovici, 2008). Esses mercados não são walrasianos; não se trata de vender bens privados, mas de negociar o acesso às diferentes redes assim constituídas, capturar parte dos consumidores/usuários e praticar uma discriminação pelos preços em função da propensão a pagar dos diferentes grupos.

Por outro lado, esses bens são bens de experiência (experience goods) (Varian, 2003): o sistema de preços não divulga para o consumidor as informações relativas à sua qualidade. Outros mecanismos sociais compensam as falhas do sistema de preços: instituições e comunidades on-line, no caso da internet.

As estratégias consistem, num primeiro momento, em desenvolver serviços gratuitos, ou semigratuitos, para os diferentes consumidores. Esses mecanismos permitem criar as redes e as externalidades que lhes correspondem, assim como divulgar as informações que o sistema de preços não tem condições de divulgar: vários produtores de softwares disponibilizam gratuitamente seus programas durante um período limitado. Certos estudos econômicos tentam determinar o nível de pirataria que maximiza o lucro do produtor de programas proprietários (Darmon, Torres e Rufini, 2008). Por outro lado, tendo em vista a ausência de suporte material no que concerne à distribuição (no caso das redes peer to peer), não é possível controlar e limitar a pirataria privada: os custos que permitiriam implementar esses processos de controle são proibitivos (Herscovici, 2007).

Em função dessas evoluções, novas formas de propriedade coletivas aparecem: os creative commons e as diferentes formas de copy left. No que diz respeito aos programas livres, a licença GPL (General Public License) pode ser qualificada como extensiva: se um componente protegido por tal licença for incorporado num outro programa, esse outro programa tem que ser regido pelo mesmo tipo de licença. De um ponto de vista mais geral, nessas novas formas de propriedade coletivas, os autores cedem parte de seus direitos privados para criar um bem público (Ostrom; Hess, 2007, p. 17). 


\section{A natureza econômica dos CT: alguns esclarecimentos epistemológicos necessários}

\subsection{Os trabalhos seminais de Coase}

O conceito de custo de transação definido por Coase em seus artigos de 1937 e 1960 representa um marco teórico importante que permite questionar a análise neoclássica "padrão"7. O autor ressalta o fato de que a economia neoclássica estuda essencialmente os mecanismos a partir dos quais o sistema de preços permite realizar a alocação eficiente dos recursos. Mostra que os custos de transação, ou seja, os custos de acesso ao mercado, são ignorados, assim como a função e as especificidades da firma.

A partir do momento em que os custos de transação existem e são positivos (Coase, 1988, p. 32), a análise de Coase se diferencia substancialmente da análise neoclássica ligada ao Equilíbrio Geral e ao Ótimo de Pareto que o caracteriza:

i) Edgeworth considera implicitamente que os agentes alcançam uma situação ótima e que essa busca se implementa sem custos. A partir do momento em que essa busca se traduz por custos de transação positivos, se esses custos foram superiores à utilidade marginal, o sistema não alcança um ótimo de Pareto (Ibid, p. 184-185).

Arrow já tinha percebido esse problema. Os custos de transação podem ser concebidos, em parte, como custos de desequilíbrio (1985, p. 78-79) em relação ao ótimo de Pareto; ou as transações se efetuam fora da posição de equilíbrio, ou os agentes precisam de tempo para calcular e alcançar essa posição. Em todos os casos, a presença de tais custos se traduz por perdas de bem-estar (Idem, p. 79). Stiglitz (2000, p. 1459) chega a uma conclusão semelhante quando afirma, a respeito da Economia da Informação, que "Coase's (1937) works explaining the 'firm' as an institution on the basis of transaction costs can be thought as a precursor of this work".

ii) Segundo a definição de Coase dos DP, a externalidade só poderá ser estabelecida após a determinação do direito dos vários agentes. O DP é concebido como o direito de usar um fator de produção e de gerar externalidades, obrigatoriamente negativas para outros agentes, até certo nível (Coase, 1960, p. 1 e 22); a externalidade será julgada negativa se ultrapassar esse nível crítico ${ }^{8}$. O agente que detém esse direito detém o direito de produzir externalidades negativas até um nível socialmente legitimado; a externalidade, positiva ou negativa, só pode

(7) Definirei a economia neoclássica "padrão" a partir das seguintes características: (a) a lei da demanda e da oferta e o market-clearing que lhe corresponde; (b) a lei do preço único; (c) a lei do preço concorrencial determinado a partir da igualação entre custo e produto marginal e (d) a hipótese dos mercados eficientes (Stiglitz, 2003, p. 13). De fato, essas características são expressas nos dois teoremas do Welfare (Stiglitz, 2000, p. 1457).

(8) A negociação dos direitos de poluição ilustra perfeitamente este tipo de situação. 
ser avaliada uma vez determinado esse valor crítico. A partir dessa definição, Coase refuta a análise de Pigou: não é possível determinar, nem avaliar objetivamente uma externalidade sem definir, anteriormente, esse valor crítico.

iii) Coase adota um critério diferente do de Pareto para avaliar a eficiência da organização social: a escolha de uma modalidade de governança deve ser realizada a partir da maximização da produção total e da minimização dos custos de transação necessários à sua implementação (1988, p. 180). Esse resultado pode implicar que a indenização dos poluídos não seja efetivamente realizada: "pode ser que o valor da produção seja mais elevado se aqueles que causaram a externalidade negativa não têm obrigação de indenizar aqueles que foram prejudicados" (Idem, p. 204), ou seja, a situação não é Pareto ótima. $\mathrm{O}$ critério de Kaldor-Hicks substituirá o critério de Pareto para avaliar a eficiência social. Nesse caso, a existência de CT corresponde a um second best (McCloskey, 1998, p. 368).

\subsection{As duas interpretações: Stigler e Williamson}

Em termos de Metodologia e História do Pensamento Econômico, é interessante observar que o paradigma neoclássico sempre tentou integrar, até certo ponto, as diferentes "heterodoxias": a leitura que Friedman e Hicks fizeram da Teoria Geral de Keynes, por exemplo, é representativa desse mecanismo. Tal integração só pode ser redutora: elimina os elementos da matriz original que ameaçam o núcleo central da teoria neoclássica, ignorando, assim, a incomensurabilidade dos paradigmas. Ela só é realizável a esse preço. Essa questão se aplica igualmente à teoria dos CT, a partir da interpretação de Stigler do conceito de CT (o Teorema de Coase) e dos desenvolvimentos posteriores de cunho neoclássico. Em oposição, a "fidelidade" da interpretação se define pelo fato de respeitar essa incomensurabilidade dos paradigmas, ou seja, pelo fato de não querer interpretar determinado conceito no paradigma que não lhe corresponde ${ }^{9}$. Mostrarei, aqui, porque a interpretação neoclássica é altamente redutora e em que medida os trabalhos de Williamson, ao contrário, são "fiéis" ao pensamento de Coase.

\subsubsection{As incompatibilidades entre a tese de Coase e a interpretação de Stigler}

A interpretação neoclássica tenta integrar esses resultados a um universo que se caracteriza pela racionalidade substantiva dos agentes e, consequentemente, pela ausência de incerteza forte. Os agentes econômicos, a partir da negociação privada, alcançam uma situação de ótimo social, geralmente Pareto ótima ou Kaldor-Hicks ótima; nesse caso, os direitos de propriedade são totalmente eficientes, os contratos são completos e os ativos não são específicos. A negociação privada dos direitos

(9) Por exemplo, não é possível, como faz Friedman (1974), assimilar a eficiência marginal do capital definida por Keynes na Teoria Geral com o conceito neoclássico de produtividade marginal do capital. 
representa a solução mais eficiente e, em última instância, os CT desaparecem no longo prazo. Na tradição friedmaniana, os CT representam imperfeições de curto prazo que desaparecem no longo prazo.

Segundo a interpretação de Stigler, na medida em que os CT são nulos, os DP eficientes, a racionalidade substantiva e os contratos completos, é possível deduzir os seguintes resultados: (a) a produção total não depende da distribuição inicial dos DP e (b) a solução que corresponde à negociação privada é sistematicamente mais eficiente que a solução pigouviana. Este último mecanismo significa que as externalidades presentes naquele mercado são totalmente endogeneizadas pelos diferentes agentes, enquanto essa endogeneização só pode ser parcial no caso de uma solução pigouviana. Essa endogeneização completa das externalidades corresponde à solução mais eficiente.

As conclusões de Coase, no seu artigo de 1960, são diferentes: a partir de uma crítica da análise de Pigou, mostram que as modalidades de intervenção pigouvianas não permitem endogeneizar totalmente as externalidades, nem realizar sistematicamente uma alocação ótima dos recursos; contrariamente ao que afirma a tese neoclássica, esse resultado não implica que a lógica privada represente a modalidade de governança mais eficiente ${ }^{10}$.

O próprio Coase refuta essa interpretação(1988, p. 7, 32 e 50). Contrariamente a Stigler, Coase afirma que: (a) é preciso considerar CT positivos; (b) a escolha de uma modalidade de organização da produção tem que corresponder àquela que minimiza os CT e (c) o mercado não minimiza, sistematicamente, tais custos; "It is clear that an alternative form of economic organization which could achieve the same result at less cost than would be incurred by using the market would enable the value of production to be raised" (Coase, 1960, p. 8). Assim, o problema consiste em comparar os diferentes modos de governança, ou seja, as diferentes modalidades de organização da produção em função de dois critérios: (a) a viabilidade do modo de governança, ou seja, o fato de os CT serem inferiores ao prejuízo inicial e (b) a eficiência dessa modalidade, ou seja, o nível dos CT que caracteriza cada modalidade de governança. As análises de Pigou ou de Stigler são enviesadas pelas mesmas razões: Pigou não considera os $\mathrm{CT}$ que correspondem à gestão burocrática, nem Stigler os CT gerados pelo jogo do mercado.

\subsubsection{As especificidades da análise de Williamson}

A análise de Williamson é totalmente incompatível com a abordagem neoclássica: em função das especificidades dos ativos, os contratos são incompletos e os DP não podem ser totalmente definidos. Nesse sentido, a incerteza comportamental

(10) Para um estudo das incompatibilidades entre a interpretação de Stigler e a análise original de Coase, ver McCloskey (1988). 
que caracteriza esse universo pode ser assimilada a uma imperfeição da informação (Barzel, 1997, p. 4) e os comportamentos dos agentes, a comportamentos oportunistas (Saussier; Yvrande-Billon, 2007, p. 11, 13). Na presença de assimetrias da informação, a situação se afasta do paradigma walrasiano e do ótimo de Pareto que o caracteriza ${ }^{11}$. Contrariamente a Stigler, Williamson desenvolveu a tese de Coase a partir das hipóteses de contratos incompletos e da racionalidade limitada dos agentes. Os DP não podem ser totalmente definidos, nem plenamente eficientes, e certos ativos são específicos.

É interessante observar que Williamson estabelece uma relação entre as particularidades do trabalho e as especificidades dos ativos (Williamson, 2002, p. 185, 188). Conclui que o trabalho qualificado pode ser concebido como um ativo específico e que, por essa razão, os contratos de trabalho são incompletos e de longo prazo. Williamson retoma e sistematiza a afirmação de Coase (1937, p. 392) segundo a qual os contratos de trabalho de curto prazo não são satisfatórios e, portanto, devem se firmar como contratos de longo prazo. As implicações são as seguintes:

i) O salário não é determinado a partir do jogo da oferta e da demanda no mercado: o trabalho é um ativo específico (Williamson, 2002, p. 185) e o sistema de preços não permite realizar uma alocação ótima.

ii) Esses contratos de longo prazo introduzem uma "rigidez" que lembra fortemente o conceito de salário de eficiência, no sentido definido por Stiglitz (2003).

A análise de Williamson é, nesse sentido, totalmente incompatível com os resultados da vertente neoclássica: em função da especificidade dos ativos, ela permite afirmar que o mercado, ou seja, a negociação privada do DP, não constitui, sistematicamente, a modalidade de governança mais eficiente, isto é, aquela que, para um mesmo nível de produção, corresponde a CT menores.

\section{Direitos de Propriedade Intelectual, governança e custos de transação}

\section{A especificidade dos ativos}

\subsection{Especificidade e complexidade}

$\mathrm{Na}$ ótica de Williamson, o volume dos custos de transação e a natureza dos contratos dependem diretamente das especificidades dos ativos considerados. Por outro lado, suas diferentes análises associam as especificidades dos ativos à "incompletude" dos contratos, à interdependência dos agentes envolvidos na transação (bilateral dependency, 2002, p. 175), à frequência das transações e ao caráter irreversível do investimento realizado.

(11) A esse respeito, ver, por exemplo, Stiglitz (2000, p. 1458). 
Em função da "heterogeneização" dos processos de produção e dos trabalhos específicos envolvidos na produção desses ativos, eles representam investimentos específicos que não têm utilizações múltiplas (Saussier; Yvrande-Billon, 2007, p. 18), o que explica seu caráter irreversível.

As especificidades desses ativos intangíveis são as seguintes:

i) Estão ligadas aos conhecimentos especializados necessários à sua produção; o sistema de DPI protege, ou tenta proteger, a utilização desse tipo de conhecimento.

ii) Investimentos importantes são realizados numa determinada direção; em função do caráter cumulativo dessas atividades, não podem ser utilizados para produzir outros bens e serviços (dedicated assets) (Williamson, 2002, p. 176). A irreversibilidade desses investimentos faz com que esse tipo de transação apresente um caráter único e, consequentemente, não repetitivo.

iii) O caráter aleatório da valorização econômica desse tipo de ativo relaciona-se diretamente com a incerteza que cerca essas atividades: a incerteza estratégica ou comportamental (Saussier; Yvrande-Billon, 2007, p. 20) provém das assimetrias da informação, do comportamento ex post dos diferentes participantes e das estratégias que eles podem desenvolver. Essa incerteza é ampliada pelo caráter cumulativo desse tipo de produção.

Essas características podem ser assimiladas a uma forma de complexidade que se manifesta tanto do lado da demanda quanto da oferta:

i) No que concerne à demanda, os bens ligados à Informação, à Cultura e ao Conhecimento são bens complexos, e sua utilidade só será conhecida durante o ato do consumo; são experience goods, e o sistema de preços não tem condições de transmitir o conjunto das informações para o consumidor.

ii) Em relação à oferta, a não homogeneidade, ou seja, as especificidades dos insumos produtivos faz com que a valorização desse tipo de produção seja particularmente aleatória ${ }^{12}$.

$\mathrm{Na}$ análise tradicional, oriunda da matriz neoclássica (Berg, 2005), os DPI são concebidos como um meio eficiente: (a) para incentivar a produção de inovação a partir de uma renda de monopólio temporária atribuída ao inovador; (b) para divulgar socialmente essa inovação e (c) para ampliar suas modalidades de apropriação social a um custo menor ${ }^{13}$. De fato, essa eficiência se relaciona com os custos de produção da inovação e ignora os custos de transação necessários à implementação econômica dessas atividades.

(12) A esse respeito, Barzel (2009, p. 33-34) menciona inputs não uniformes e a valorização aleatória desse tipo de output.

(13) Os conceitos de eficiência estática e dinâmica explicam esses mecanismos. 


\subsection{Especificidade dos ativos, custos de transação e governança}

A problemática que norteia o conjunto das análises de Williamson consiste em estabelecer uma correlação positiva entre a especificidade dos ativos e o volume dos custos de transação no âmbito do jogo de mercado (2002, p. 180). Williamson mostra que, para cada tipo de ativo, em função de seu grau de especificidade, há uma modalidade de governança que permite diminuir os custos de transação. Assim, o mercado não representa sistematicamente a instância que minimiza esses custos: "Transaction cost economizing is the unifying concept" (Williamson, 2002, p. 180).

Por outro lado, conforme reconhece o próprio Williamson (Idem), investimentos em ativos específicos só ocorrem quando correspondem a uma redução dos custos de produção ou a rendas suplementares; a segunda característica aplica-se ao caso aqui analisado. Não obstante, a Economia da Informação e do Conhecimento caracteriza-se pela desconexão entre os custos e as receitas (Herscovici, 2008). Essa particularidade explica o caráter especulativo dessa economia: no âmbito de uma economia rentista, esses investimentos são cada vez mais ligados ao fato de poder auferir, potencialmente, mais-valias financeiras e lucros "extraordinários".

Uma maneira de reduzir essa incerteza consiste em aumentar os custos ligados ao estabelecimento de contratos. É preciso, portanto, examinar a natureza da incerteza e as possibilidades que oferece o contrato para diminuí-la. Os custos de transação são constituídos pelas cláusulas de segurança, as penalidades, as assimetrias da informação, os dispositivos de verificação e a resolução dos conflitos por uma instância externa e, obviamente, pelos custos relativos aos contratos (Williamson, 2002, p. 183). No caso neoclássico, o ativo não apresenta especificidade - não há custos de transação - e o mercado representa a instância de regulação mais eficiente (a hipótese dos mercados contingentes, no modelo Arrow-Debreu, por exemplo). Ao contrário, quando o ativo se torna específico, a governança de mercado se traduz por um aumento dos custos de transação; nesse caso, uma integração intrafirma, uma gestão pública ou uma forma híbrida podem resultar, para um mesmo nível de especificidade, em custos de transação menos elevados (Williamson, 2002, p. 183; 2000, p. 604).

Williamson observa que, no âmbito de uma lógica de mercado, quanto maior a incerteza, ou seja, quanto menor a segurança apresentada pelo ativo, maior seu preço. Nesse caso, está embutido, no preço, um prêmio de risco (2000, p. 604) uma regulação que se afasta da regulação de mercado é preferível quando o aumento dos preços ligados à incerteza é superior ao aumento dos custos de transação que permitem reduzir essa incerteza. A escolha de uma modalidade de governança depende da razão entre o aumento dos preços devido à existência da incerteza e os custos de transação necessários para diminui-la. 
É necessário, portanto, analisar a natureza dos contratos em relação à especificidade do ativo, à existência de relações bilaterais e aos direitos de propriedade. Para a economia neoclássica, os agentes atuam a partir de uma racionalidade substantiva, maximizam funções microeconômicas de utilidade e de lucro e têm condições de avaliar as implicações, ou seja, as externalidades provocadas pela sua atuação. A racionalidade substantiva e a existência de contratos "completos" são as condições necessárias e suficientes para maximizar a função de bem-estar social. A esse respeito, Coase afirma que, a partir do momento em que os custos de transação são nulos, "(...) all that matters (...) is that the rights of the various parties should be well-defined and the result of legal actions easy to forecast." (1960, p. 10).

Quando os ativos são específicos, ao contrário, a problemática muda radicalmente: o mercado não representa a instância que permite minimizar, sistematicamente, os custos de transação. A dependência bilateral e o aparecimento de rendas e quase rendas podem incentivar o surgimento de comportamentos oportunistas, o que explica porque o mercado não constitui a modalidade de governança mais eficiente. Assim, os contratos "neoclássicos" se relacionam com o longo prazo e são incompletos por definição (Saussier; Yvrande-Billon, 2007, p. 32). As conclusões formuladas por Barzel (1997, p. 7) são semelhantes: na medida em que os custos de transação têm por função a transferência e a proteção dos DP, custos de transação positivos implicam que os DP não podem ser plenamente definidos e que, consequentemente, os contratos são incompletos.

\subsection{Da racionalidade limitada à incerteza: rumo a uma análise institucionalista}

Qual é a natureza da incerteza nas diferentes análises institucionalistas? Williamson adota a hipótese de racionalidade limitada. Há duas respostas possíveis:

i) A incerteza é inteiramente definida pelos limites cognitivos dos agentes, e o universo é ergódico (Slater; Spencer, 2000). Nesse sentido, não há incerteza forte no sentido pós-keynesiano (Idem, p. 61).

ii) A segunda resposta ressalta o fato de que há uma relação estreita entre esses dois tipos de incerteza: na presença de comportamentos oportunistas, não é possível prever todos os estados do mundo possíveis. A incerteza comportamental se traduz por incerteza forte ${ }^{14}$ e a especificidade dos ativos é uma variável endógena (Saussier; Yvrande-Billon, 2007, p. 75), o que explica a existência de estratégias que visam auferir as rendas de monopólio a partir do sistema de DPI vigente.

Minha interpretação de Williamson relaciona-se diretamente com a segunda resposta: a incerteza forte permite justificar o fato de os contratos serem incompletos. Para outros economistas institucionalistas, os contratos são incompletos

(14) É igualmente a posição de Greenwald e Stiglitz (1987, p. 125). 
e o sistema de DP “imperfeito” por natureza. Barzel (1997, p. 4) afirma que custos (de transação positivos correspondem a sistemas intrinsecamente imperfeitos de DP e, consequentemente, ao fato de os agentes não possuírem uma informação perfeita (full knowledge) a respeito do ativo e dos retornos esperados. Essas imperfeições se explicam, simultaneamente, pelas diferentes assimetrias da informação e pelo caráter não ergódico do universo.

Há, nos escritos de Coase, certas ambiguidades que Williamson reproduz, em parte. Por um lado, Coase demonstra que a firma surge para minimizar os custos a partir de uma comparação entre o custo da atividade quando organizada na empresa e quando realizada no mercado, ou seja, fora da empresa. O tamanho da firma se explica a partir desse custo diferencial; a firma alcança o tamanho ideal quando minimiza seus custos (1937, p. 395). Coase afirma, por outro lado, que existe incerteza (1937, p. 392). A contradição aparece à medida que é impossível minimizar uma função de custos no universo que se caracteriza pela incerteza forte.

A mesma contradição reaparece na análise de Williamson: sua problemática consiste em escolher a modalidade de governança que permite economizar os custos de transação para um determinado nível de especificidade dos ativos (2002, p. 180). Se economizar significa minimizar, aparece a seguinte contradição: o próprio processo de minimização dos custos de transação implica que o agente atue a partir de uma racionalidade substantiva em um universo ergódico; assim, é impossível conciliar racionalidade limitada e não ergodicidade com escolhas que minimizam os custos de transação. Em última instância, considerando que o universo é ergódico, os custos de transação são negligenciáveis no longo prazo e o mercado representa a instância de regulação mais eficiente (Slater; Spencer, 2000, p. 79; Langlois; Robertson, 1995). ${ }^{15}$

No âmbito de uma perspectiva ligada ao "Velho Institucionalismo", escolho a tese da incerteza forte: essa escolha não permite minimizar os custos de transação, mas chegar a uma situação intermediária entre o nível mais alto e o mais baixo; um nível julgado satisfatório (satisficing approach) (Williamson, 2002, p. 174).

\section{A escolha de uma modalidade de governança}

\subsection{A problemática de Stigler}

A análise de Stigler será utilizada, num primeiro momento, como um marco zero para determinar a modalidade de governança mais eficiente quando os CT são nulos. Não obstante, em função das observações metodológicas feitas neste trabalho, relaxarei essa hipótese para avaliar a eficiência real dessas diferentes modalidades.

(15) Milton Friedman (1974, p. 48) chega a resultados semelhantes quando afirma que o longo prazo é um estado que se caracteriza pelo fato de as expectativas se realizarem sistematicamente. 
O "Teorema de Coase" pode ser ilustrado pelo seguinte exemplo ${ }^{16}$ : supondo que dois agentes econômicos, $\mathrm{X}$ e $\mathrm{Y}$, tenham, cada um, uma casa, e que Y resolva testar sirenes de alarme, essa atividade se traduz por um aumento da utilidade avaliado em $500 \$$ para $\mathrm{Y}$ e por uma diminuição da utilidade, avaliada em 200\$ para X. O Quadro 1 permite enunciar os seguintes resultados:

Proposição 1: a utilidade social é maior com a implementação da atividade, conforme ressalta a comparação entre 1 e 2 .

Proposição 2: quando os custos de transação são nulos no âmbito de uma negociação privada, o bem-estar social é independente da alocação inicial dos DP. As situações 3 e 4 ilustram essa afirmação.

Proposição 3: em termos de bem-estar social, a negociação privada é preferível à regulação estatal, conforme mostra a comparação entre 3 e 4, de um lado, e 5, de outro. Nesse caso, a regulação consiste em impedir a implementação da atividade econômica que produz externalidades negativas.

Proposição 4: a comparação entre 3, 4, 6 e 7 mostra claramente que essas situações são equivalentes, do ponto de vista do bem-estar social, quando os custos de transação são iguais a zero.

Quadro 1

Uma reinterpretação do "Teorema de Coase"

\begin{tabular}{|c|c|c|c|c|}
\hline & Utilidade de X & Utilidade de Y & \multicolumn{2}{|c|}{ Utilidade total } \\
\hline Sem alarme & $12(00$ & 1000 & 2200 & 1 \\
\hline Com alarme & 1000 & 1500 & 2500 & 2 \\
\hline Com negociação & 1200 & 1300 & 2500 & 3 \\
\hline Sem negociaçāo & 1000 & 1500 & 2500 & 4 \\
\hline \multicolumn{5}{|c|}{ A alternativa institucional } \\
\hline Reggulação pigouviana & 1200 & 1000 & 2200 & 5 \\
\hline Taxa pigouviana & 1300 & 1200 & 2500 & 6 \\
\hline Regulaçào institucional & 1200 & 1300 & 2500 & 7 \\
\hline
\end{tabular}

Se, ao contrário, consideramos que cada solução se caracteriza por custos de transação positivos, a eficiência de cada modalidade de governança depende dos níveis de custos de transação respectivos; nada indica que a negociação privada corresponda ao menor nível de custos de transação.

O bem-estar gerado por cada modo de governança depende dos custos de transação que lhe são associados. A análise neoclássica, a priori, considera que os custos de transação próprios à negociação privada são menores quando comparados a uma intervenção pública em função da ineficiência que caracteriza a gestão burocrática (Buchanan e Tullock, 1962). Williamsom, ao contrário, mostra que o mercado, ou seja, a negociação privada, não corresponde, sistematicamente, à solução mais eficiente.

(16) Este exemplo provém de Pejovich (1995). 


\subsection{A escolha do critério de eficiência social e as externalidades}

A posição de Coase é perfeitamente clara a respeito da posição de Pigou e das externalidades negativas. Afirma que "Pigou is, of course, quite right to describe such actions as " uncharged disservices ». But he is wrong when he describes these actions as 'anti-social"', (1960, p. 18). Assim, segundo Coase, o bem-estar social corresponde à maximização da utilidade coletiva, independentemente de qualquer lógica de redistribuição e de um eventual aumento da desigualdade.

$\mathrm{Na}$ medida em que o critério de Pareto incorpora uma dimensão redistributiva, a concepção coasiana não é eficiente. Essa análise torna necessária a construção de um outro critério para avaliar o bem-estar social: o critério de KaldorHicks. O mecanismo é o seguinte: se A realiza um ganho de $100 \$$, mas produz uma externalidade negativa de $30 \$$ para $\mathrm{B}$, e se $\mathrm{A}$ indeniza $\mathrm{B}$ para um valor de $30 \$$, essa situação corresponde a um ótimo de Pareto; nenhum indivíduo prefere um outro estado, e o aumento da produção total é de 70\$. Nesse raciocínio, simplificado ao extremo, os custos de transação são nulos

Quando os custos de transação são positivos, a indenização dos agentes prejudicados não é efetiva nem sistematicamente realizada. Supondo que os custos de transação sejam de $80 \$$ e a externalidade negativa de $30 \$$, se a indenização for efetivamente realizada, a produção total vai diminuir $10 \$$; ao contrário, se a indenização não for realizada, a utilidade total aumenta $70 \$$. O estado que corresponde a não efetivação da indenização é eficiente em relação ao critério de Kaldor-Hicks à medida que a produção total aumenta; mas ele não é eficiente em relação ao critério de Pareto. O critério de Kaldor-Hicks corresponde ao aumento da utilidade social, ou seja, a uma alocação eficiente dos direitos em relação ao aumento da produção, embora ignore as implicações em termos de distribuição da renda e da desigualdade. Se a utilidade total aumenta, os desvios entre poluidores e poluídos aumentam igualmente.

A aplicabilidade do critério de Kaldor-Hicks depende diretamente das seguintes hipóteses: (a) os direitos dos diferentes agentes são totalmente identificáveis e quantificáveis; (b) esses direitos são transferíveis de um agente para outro e (c) os custos relativos ao controle dos comportamentos oportunistas não são proibitivos. No caso de essas hipóteses serem verificadas, o mercado representa o modo de governança mais eficiente ${ }^{17}$.

É possível formalizar essas relações da seguinte maneira:

Produto marginal do capital $\geq$ taxa pigouviana + custo marginal do capital

$$
\text { Taxa pigouviana } \geq \text { desutilidade }
$$

(17) Apresenta-se, novamente, a seguinte contradição: como maximizar uma função microeconômica de lucro em um universo que se caracteriza pela incerteza forte? Como conciliar DP totalmente definidos e CT positivos? 
A relação (1) significa que o agente poluidor vai aumentar sua produção até o ponto no qual o produto marginal do capital se torne igual ao seu custo marginal e à taxa pigouviana. A relação (2) mostra que o poluído aceitará a taxa pigouviana até esta se tornar igual à desutilidade provocada pela poluição. Nesse raciocínio, os custos de transação são nulos.

O critério paretiano de maximização corresponde à verificação simultânea das duas relações seguintes:

$$
\begin{aligned}
& P m=T P+C m \\
& T P=\text { desutilidade }
\end{aligned}
$$

( $P m$ representa o produto marginal, $\mathrm{Cm}$ o custo marginal e $T P$ a taxa pigouviana)

A alocação dos DP, assim realizada, maximiza o bem-estar social sem aumentar as desigualdades em termos de distribuição de renda.

O critério de Kaldor-Hicks, ao contrário, considera apenas a relação (3): a produção só aumentará enquanto $P m$ permanecer superior a $(T P+C m)$. O critério de Kaldor-Hicks privilegia apenas o aumento da produção como medida de bem-estar social. É justamente por essa razão que a taxa pigouviana não será implementada. O fato de eliminar essa taxa permite continuar a aumentar a produção, mas amplia as desigualdades em termos de utilidade e de renda.

\section{Limites das modalidades de negociação privada dos DPI}

\subsection{Os limites da negociação privada: a impossibilidade de exercer uma racionalidade substantiva}

Para que os agentes econômicos possam negociar no âmbito de um mecanismo privado e exercer uma racionalidade substantiva é preciso que seja possível avaliar ex ante: (a) o produto marginal do poluidor e (b) o custo que corresponde a desutilidade do poluído.

Essas condições não são verificadas nas seguintes situações:

i) Em função da complexidade e da especificidade dos ativos considerados, o caráter especulativo e particularmente aleatório da valorização desses ativos não permite avaliar, ex ante, o produto marginal; consequentemente, não é possível maximizar o lucro.

ii) Caso o poluidor tenha que compensar o poluído, seu custo corresponderá à desutilidade do poluído e, na medida em que se trata de valor subjetivo, essa desutilidade varia em função dos diferentes agentes. Assim, não é possível avaliar, ex ante, esse custo eventual. 
A análise neoclássica considera apenas os custos de transação ex ante e ignora voluntariamente os custos de transação ex post (Zylbersztajn, 2003, p. 6). Essa abordagem é coerente com as hipóteses de contratos completos, de racionalidade substantiva e de delimitação perfeita dos DP. Não obstante, surge o seguinte paradoxo: se os contratos são completos e os DP perfeitamente delimitados, na ausência de incerteza, os custos de transação são nulos (Barzel, p. 7, 11), o que corresponde à interpretação de Stigler. Mas, nesse caso, a análise institucionalista pode ser assemelhada à análise walrasiana, e os custos de transação representam apenas uma rigidez de curto prazo que desaparece obrigatoriamente no longo prazo. Coase afirma, no seu artigo de 1937, que CT nulos não permitem explicar a existência da firma.

iii) Considerando-se que a racionalidade é limitada, não é possível avaliar todas as externalidades negativas e positivas geradas pela utilização de um determinado ativo. Não é possível avaliar a desutilidade do poluído, nem o produto marginal do poluidor.

iv) O mecanismo de maximização neoclássico implica que o produto marginal dos diferentes fatores de produção seja decrescente (relação (1)). A produção de conhecimento é, por natureza, cumulativa: seu produto marginal é crescente ${ }^{18}$, não sendo possível maximizar uma função de produção.

Em síntese, pode-se afirmar que os limites da análise neoclássica provêm do fato de que as especificidades do capital intangível são voluntariamente ignoradas.

\subsection{Custo tecnológico, DPI privados e falhas de mercado}

Em função da dependência bi e multilateral, é possível considerar a seguinte situação: duas firmas A e B (é igualmente possível considerar $n$ firmas) oferecem, cada uma, um componente que faz parte de determinado processo tecnológico, sendo cada um desses componentes complementar: por exemplo, cada firma oferece um algoritmo informático, e a produção de um programa novo depende desses dois algoritmos.

$$
\begin{gathered}
P a=p a \cdot q a+E a / b \\
P b=p b \cdot q b+E b / a \\
T C=p a \cdot q a+p b \cdot q b
\end{gathered}
$$

$T C$ representa o custo tecnológico, $p$ representa o preço praticado pela firma para ceder seus direitos, $q$, as "quantidades" vendidas e $T C$, o custo relativo à aquisição do conjunto do processo tecnológico. Eb/a representa a externalidade produzida por A e endogeneizada por $\mathrm{B}$, e $E a / b$, a externalidade produzida por $\mathrm{B}$ e endogeneizada por $\mathrm{A}$.

(18) Essa hipótese é adotada nos diferentes modelos de crescimento endógeno. 
Se, inicialmente, A diminui seus preços e B mantém seus preços constantes, B se beneficia de uma externalidade de demanda produzida por A: $E a / b=0$, e $E b / a$ é positiva. Aparecem, assim, falhas de coordenação: a queda dos preços praticada por A depende das expectativas de $\mathrm{A}$ em relação às estratégias desenvolvidas por $\mathrm{B}$. Se A prevê que B vai manter seus preços constantes, não vai sistematicamente diminuir seus preços. Assim, o mercado não constitui um mecanismo eficiente, na medida em que ele não minimiza sistematicamente os custos da tecnologia. Nos casos 2, 3 e 4, TC é mais elevado do que seria se tivesse apenas um detentor dos direitos: essa situação se explica a partir do comportamento oportunista de certos agentes.

A existência de externalidades de demanda ressalta as falhas de coordenação que estão surgindo nesse mercado e o equilíbrio subótimo que lhe é relacionado. No exemplo aqui utilizado, A não tem interesse em baixar seu preço se B mantém seu preço constante; não haverá, portanto, queda dos preços dessas patentes. Em todos os casos, haverá uma subaditividade dos custos relativos à aquisição desses direitos na medida em que o preço necessário para utilizar aquela tecnologia será superior ao que prevaleceria se houvesse apenas um detentor de direito.

Quadro 2

As falhas de coordenação

\begin{tabular}{|c|c|c|}
\hline & $\searrow$ pa & pa constante \\
\hline$\searrow$ pb & 1 & 2 \\
\hline pb const. & 3 & 4 \\
\hline
\end{tabular}

A situação (1) é a única eficiente, na medida em que TC é minimizado.

Em relação a essa subotimalidade, a implementação de uma taxa pigouviana (Rosenkranz e Schmitz, 2006), ou de qualquer outro princípio de coerção, pode neutralizar os efeitos ligados aos comportamentos oportunistas. Esse princípio de coerção pode ser representado por convenções, regras implícitas ou explícitas próprias a determinado clube ou coletividade, crenças, efeitos de reputação e instituições.

$$
\begin{aligned}
P a & =p a . q a \\
P b & =p b . q b+E b / a-E C \\
T C & =p a . q a+p b . q b
\end{aligned}
$$

A taxa de crescimento do efeito de coerção $(E C)$ deve ser superior à taxa de crescimento de $p b . q b$; assim, o mecanismo implementado deve neutralizar $E b / a$ e 
incitar B a diminuir seus preços relativos, o que permite eliminar os comportamentos oportunistas.

Esse paradoxo pode ser enunciado da seguinte forma: no âmbito de uma negociação privada, a eficiência do mercado depende diretamente da intervenção do Estado ou das diferentes formas institucionais. Os mecanismos de negociação privada dos direitos são compatíveis com o bem-estar social apenas quando existe uma intervenção institucional que permite neutralizar os diferentes comportamentos oportunistas.

\section{Observações finais}

Este estudo preliminar permite formular as seguintes conclusões: a extensão atual do sistema de DPI e de seus componentes mercantis relaciona-se diretamente com a interpretação neoclássica do conceito de CT. A crítica elaborada neste trabalho mostra claramente que essas escolhas metodológicas são pouco apropriadas para analisar os ativos intangíveis ligados à Informação e ao Conhecimento e para determinar as modalidades de governança mais eficientes. Esses limites se explicam a partir das especificidades dos ativos e dos diferentes tipos de assimetrias da informação que caracterizam esses mercados.

A regulação de mercado se traduz, na maior parte dos casos, por um aumento dos custos de transação e por várias “falhas”. É, necessário, portanto, incorporar, na análise, as especificidades dos ativos, suas implicações no que diz respeito à dinâmica dos mercados e determinar modalidades de governança adequadas.

Finalmente, é interessante observar que a eficiência, ou, pelo menos, o funcionamento "satisfatório" do mercado, depende diretamente de variáveis institucionais e não apenas das modalidades de negociação privada. Este resultado ressalta as complementaridades entre o econômico e o extraeconômico, entre o mercado e as instituições; resultado, esse, semelhante aos do "Velho Institucionalismo", que explica as diferentes modalidades de funcionamento do sistema sem ter que recorrer às hipóteses "heroicas" de racionalidade substantiva, de ergodicidade e de maximização microeconômica.

\section{Bibliografia}

ALCHIAN, Armen A.; DEMSETZ, Harold. The property rights paradigm. The Journal of Economic History, v. 3, n. 1, p. 16-27, 1973.

ARROW, Kenneth J. Economic welfare and the allocation of resources for invention. In: THE RATE and direction of inventive activities: economic and social factors. Princeton University Press, 1962. p. 609-26. 
ARROW, Kenneth J. The potential and limits of the market in resources allocation. In: FEIWEL, G. R. (Ed.). Issues in contemporary microeconomics and welfare. London: Macmillan, 1985. p. 107-124.

BARZEL, Yoram. Economic analysis of property rights. Cambridge University Press, 1997.

BERG, Roger van der. Property rights and the creation of wealth. American Law and Economics Review, v. 5, n. 1, 2003.

BOWLES, Samuel; HERBERT, Gintis. Social capital and community governance. 2001. (Working Paper, 03-04-027). Disponível em: www.santafe.edu/sfi/publications/. . Acesso: 1 jul. 2004.

BUCHANAN, James M.; TULLOCK, Gordon. The calculus of consent. University of Michigan Press. 1962.

COASE, R. H. The nature of the firm. Economica, New Series, v. 4, n. 16. p. 386-405, Nov. 1937.

. The problem of social cost. Journal of Law and Economics, 3, 1960.

. The firm, the market and the law. University of Chicago Press, 1988.

COX, Susan Jane Buck. No tragedy on the commons. In: WORKSHOP in Political Theory and Policy Analysis. Indiana University, 1986. (Discussion Papers).

DARMON, E.; RUFINI, A.; TORRE, D. Back to software "profitability piracy": The role of delayed adoption and information diffusion. Colloque Services on line. Université de Paris 11, Sceaux, 2007.

DEMSETZ, Harold. The exchange and enforcement of property rights. Journal of Law and Economics, v. 7, p. 11-26, 1964.

FORAY, Dominique. L'économie de la connaissance. Paris: La Découverte, 2000.

FRIEDMAN, Milton. Comments on the critics. In: GORDON, R. J. (Ed.). Milton Friedman's monetary framework: a debate with his critics. Chicago: University of Chicago Press, Chicago, 1974.

HARDIN, Garret. The tragedy of the commons. Science, v. 162, p. 1243-1248, 1968.

HELLER, M.; EISENBERG, R. Can patent deter innovation? The anticommons tragedy in biomedical research. Science, v. 29, p. 698-701, 1998.

HERSCOVICI, Alain. Information, qualité et prix : une analyse économique de l'internet et des réseaux d'échange d'archives. Congrès International. Online services ADIS/Université de Paris Sud, Paris, décembre 2007.

. Direitos de propriedade intelectual, novas formas concorrenciais e externalidades de redes. Uma análise a partir da contribuição de Williamson. Seminário de Pesquisa, IE/ UFRJ, Rio de Janeiro, 2008. 
KATZ, M. L.; SHAPIRO, C. Network externalities, competition and compatibility. American Economic Review, v.75, n. 3, 1985.

LEBAS, Christian. Fonctionnement, transformation et tensions du système de brevet. Les implications du "cours pro-brevet" à la lumière des études empiriques récentes. Revue d'Economie Industrielle, Paris, n. 99, 2ème trimestre, 2002.

McCLOSKEY, Deirde. The so-called coase theorem. Eastern Economic Journal, v. 24, n. 3, Summer, 1998.

NELSON, R. Markets and the scientific commons. Columbia University, 2003. (Working Paper).

ORSI, Fabienne. La constitution d'un nouveau droit de proriété intellectuelle sur le vivant aux États-Unis: origine et signification d'un dépassement de frontière. Revue d'Economie Industrielle, n. 99, 2ème trimestre, 2002.

OSTROM, Elinor. Private and common property rights. In: WORKSHOP in Political Theory and Policy Analysis. Population and Environmental Change. Indiana University, 2000.

OSRTOM, Elinor; CHARLOTTE, Hess. A framework for analyzing the knowledge commons. In: HESS, Charlotte; OSTROM, Elinor (Ed.). Understanding knowledge as a commons. Cambridge, Massachusetts, London: The MIT Press, 2007.

PEJOVICH, S. Economic analysis of institutions and systems. Dordrecht-Boston, London: Kluwer Academic Publishers, 1995. (International Studies in Economics and Econometrics, v. 33).

POSNER, Richard A. Intellectual Property: the law and economics approach. Journal of Economic Perspectives, v. 19, n. 2, p. 57-73, Spring 2005.

ROMER, Paul. Endogenous technological change. Journal of Political Economy, v. 98, n.5, 1990.

. When whould we use Intellectual Property Rights. American Economic Review, v. 92, n. 2, May 2002.

ROSENKRANZ, S.; SCHMITZ, P. W. Can Coasean bargaining justify Pigouvian taxation? Bonn Econ. Discussion Paper. Bonn, Feb. 2006. (Discussion Paper, n. 7).

SALOP, Steve. Information and monopolistic competition. American Economic Review, v. 66, n. 2, May 1976.

SAUSSIER, Stéphane; ANNE, Yvrande-Billon. Économie des coûts de transaction. Paris: La Découverte, 2007.

SLATER, Gary; SPENCER, David. The uncertain foundations of transaction costs. Journal of Economic Issues, v. XXXIV, n. 1, Mar. 2000.

STIGLER, George J. The theory of price. 3rd. ed. New York: Macmillan \& Co., 1966.

STIGLITZ, Joseph E. The contribution of the economics of information to twentieth century economics. The Quarterly Journal of Economics, Nov. 2000. 
STIGLITZ, Joseph E. Information and the change in the paradigm in economics, Part 1. American Economist, p. 6-26, Fall 2003.

; GREENWALD, B. Keynesian, new Keynesian and new classical economists. Oxford Economic Papers, 39, p. 119-132, 1987.

VARIAN, H. R. Economics of information technology. Mar. 2003.

WILLIAMSON, Oliver E. The new institutional economics: taking stock, looking ahead. Journal of Economic Literature, v. XXXVIII, Sept. 2000.

. The theory of the firm as governance structure: from choice to contract. Journal of Economic Perspectives, v. 16, n. 3, Summer 2002.

ZYLBERSZTAJN, Decio. Costs, transactions and transaction costs: are there simple answers for complex questions? São Paulo: Faculdade de Economia, Administração e Contabilidade / Universidade de São Paulo, 2003. (Working Papers). 